\section{No association between cortical lesions and leptomeningeal enhancement on 7-Tesla MRI in multiple sclerosis}

\author{
Mehrnaz Ighani, Samuel Jonas, Izlem Izbudak, Seongjin Choi, Alfonso Lema-Dopico, \\ Jun Hua, Erin E O’Connor and Daniel M Harrison iD
}

\section{Abstract}

Background: Autopsy data suggest a causative link between meningeal inflammation and cortical lesions (CLs) in multiple sclerosis (MS).

Objective: To use leptomeningeal enhancement (LME) and CLs on 7-Tesla (7T) magnetic resonance imaging (MRI) to investigate associations between meningeal inflammation and cortical pathology.

Methods: Forty-one participants with MS underwent 7T MRI of the brain. CLs and foci of LME were quantified.

Results: All MS participants had CLs; 27 (65.8\%) had $>1$ focus of LME. Except for hippocampal CL count $(\rho=0.32$ with spread/fill-sulcal pattern LME, $p=0.042)$, no significant correlations were seen between LME and CLs. Mean cortical thickness correlated with the number of LME foci $(\rho=-0.43$, $p=0.005$ ). Participants with relapsing-remitting multiple sclerosis (RRMS) showed no correlation with neocortical CLs, but significant correlations were seen between LME and hippocampal lesion count $(\rho=0.39, p=0.030)$, normalized cortical gray matter $(\mathrm{GM})$ volume $(\rho=-0.49, p=0.005)$, and mean cortical thickness $(\rho=-0.59, p<0.001)$.

Conclusion: This study supports a relationship between LME and cortical GM atrophy but does not support an association of LME and neocortical CLs. This may indicate that meningeal inflammation is involved with neurodegenerative inflammatory processes, rather than focal lesion development.

Keywords: Leptomeningeal enhancement, meningeal inflammation, cortical lesions, hippocampal lesions, multiple sclerosis, 7T MRI, 7 Tesla

Date received: 3 June 2019; revised: 12 August 2019; accepted: 14 August 2019.

\section{Introduction}

Cortical gray matter (GM) pathology is a strong determinant of disability in multiple sclerosis (MS). The development of lesions in the cortex, typified by demyelination, microglial activation, and reduced neuronal density, may lead to many of the more disabling aspects of MS, such as cognitive dysfunction, fatigue, and neuropsychiatric symptoms. ${ }^{1,2}$ The mechanism of cortical lesion (CL) development in MS is still unclear. While white matter (WM) lesions may develop through perivascular inflammatory mechanisms, most CLs do not have a clear association with vasculature. ${ }^{1,3}$ Furthermore, although pathologic analysis of WM lesions reveals highly cellular, lymphocytic infiltrates, most CLs are comparatively pauci-cellular. ${ }^{1,3}$
The association noted at autopsy between leptomeningeal inflammation and CLs provides a potential clue toward the mechanism of CL development. Meningeal inflammatory infiltrates are found in most patients with MS and $40 \%-50 \%$ of subjects with secondary progressive multiple sclerosis (SPMS) have ectopic lymphoid follicles in the leptomeninges., 4 Autopsy data suggest that patients with leptomeningeal follicles are prone to increased cortical demyelination and neuronal loss. ${ }^{4,5}$ Furthermore, the degree of demyelination and neuronal loss in the cortex follows a gradient emanating from nearby leptomeningeal lymphoid follicles. ${ }^{6}$ This association, supported from data in rodent models of MS, invokes diffusing cytokines, antibodies, and complement originating from these follicles as triggers for microglial
Multiple Sclerosis Journal 2020, Vol. 26(2) 165-176 DOI: 10.1177 1352458519876037

(C) The Author(s), 2019. Article reuse guidelines: sagepub.com/journalspermissions
Correspondence to: DM Harrison

Department of Neurology, University of Maryland School of Medicine, 110 South Paca Street, 3rd Floor, Baltimore, MD 21201, USA. dharrison@som. umaryland.edu

Mehrnaz Ighani University of Maryland, College Park, MD, USA

Samuel Jonas Department of Radiology, University of Maryland Medical Center, Baltimore, MD, USA

Izlem Izbudak

Department of Radiology and Radiological Sciences, Johns Hopkins University School of Medicine, Baltimore, MD, USA

Seongjin Choi Alfonso Lema-Dopico Department of Neurology, University of Maryland

School of Medicine, Baltimore, MD, USA

Jun Hua

Department of Radiology and Radiological Sciences, Johns Hopkins University School of Medicine, Baltimore, MD, USA/Department of Neurology, University of Maryland School of Medicine, Baltimore, MD, USA/F.M. Kirby Research Center for Functional Brain Imaging, Kennedy Krieger Institute, Baltimore, MD, USA

Erin E O'Connor

Department of Radiology and Nuclear Medicine, University of Maryland School of Medicine, Baltimore, MD, USA

Daniel M Harrison Department of Neurology, University of Maryland School of Medicine, Baltimore, MD, USA Department of Neurology, Johns Hopkins University School of Medicine, Baltimore, MD, USA 
activation, inflammatory cell recruitment, and direct toxicity to adjacent cortex..$^{7,8}$ Despite biological plausibility and supportive data, the direct pathologic link between CLs and meningeal inflammation remains a controversy as some autopsy series find no signs of meningeal follicles and no relationship between CLs and meningeal inflammation. ${ }^{9,10}$

Given conflicting pathologic data, it is critical to provide in vivo confirmation of the hypothetical link between CLs and meningeal inflammation in living MS patients. The use of ultra-high-field magnetic resonance imaging (MRI) may provide such an opportunity. Visualization of CLs by 7-Tesla (7T) MRI is superior to lower fields, ${ }^{11}$ and quantification of CL burden in patients with MS by 7T MRI reveals pathology causative of disability. ${ }^{12,13}$ Newer acquisition methods, such as magnetization-prepared 2 rapid acquisition gradient echoes (MP2RAGE), have refined the ability of 7T MRI to accurately assess cortical pathology in MS. ${ }^{14}$

Leptomeningeal enhancement (LME) on contrastenhanced fluid-attenuated inversion recovery (FLAIR) MRI is emerging as a biomarker of meningeal inflammation in MS patients. ${ }^{15}$ Use of this technique at $7 \mathrm{~T}$ revealed LME with gadolinium in $90 \%$ of subjects in a cohort of MS patients. ${ }^{16}$

Analysis of imaging methods for cortical GM pathology and LME can help confirm or refute the link between these two pathologic entities. Indeed, studies at both 3-Tesla (3T) and 7T consistently show reductions in cortical GM volume (indicating GM atrophy) in MS subjects with LME. ${ }^{15-18}$ In this paper, the authors aim to delve deeper into this association, using the superior capabilities of 7T MRI to visualize CLs and LME to further investigate the link between CLs and meningeal inflammation in MS.

\section{Methods}

\section{Participants}

Protocols were approved by the Institutional Review Boards at the University of Maryland School of Medicine, the Johns Hopkins University School of Medicine, and the Kennedy Krieger Institute. Written informed consent was obtained from all participants. Volunteers aged 18-65 with diagnoses of relapsingremitting multiple sclerosis (RRMS), SPMS, and primary progressive multiple sclerosis (PPMS) according to revised 2010 McDonald Criteria ${ }^{19}$ were recruited. Participant study visits included demographic and clinical data collection and a neurological examination for calculation of the Expanded Disability Status Scale (EDSS) score. ${ }^{20}$ Healthy volunteers were recruited for comparison.

\section{MRI protocol}

Participants underwent MRI in a 7T Philips Achieva scanner with a volume transmit/32-channel receive head coil (Novamedical, Wilmington, MA, USA). Details of our MRI protocol, including acquisition parameters, have been previously described. ${ }^{16,21}$ In brief, magnetization-prepared fluid-attenuated inversion recovery (MPFLAIR) and MP2RAGE sequences were obtained at $0.7 \mathrm{~mm}^{3}$ resolution across the whole brain before and after intravenous administration of $0.1 \mathrm{mmol} / \mathrm{kg}$ of gadoteridol (ProHance ${ }^{\circledR}$; Bracco Imaging, Milan, Italy).

\section{Image processing and analysis}

MP2RAGE images were processed to create a T1-weighted (T1-w) image and T1 map. ${ }^{22}$ A denoised T1-w image was also created by multiplying the second inversion-time image in the MP2RAGE acquisition (after N4 inhomogeneity correction) ${ }^{23}$ and the corresponding T1-w image. Images were subsequently manipulated in Medical Image Processing, Analysis, and Visualization (MIPAV; version 7.2, http://mipav. cit.nih.gov) and an analysis pipeline was created with Java Image Science Toolkit (JIST; version 3.0, https:// www.nitrc.org/projects/jist). MPFLAIR images were registered to the denoised T1-w image, which was also used for skull stripping.

Our methods for identification and classification of foci of LME on 7T MRI have been described in two prior publications. ${ }^{16,21}$ In brief, subtraction MPFLAIR images (post-contrast minus pre-contrast) were reviewed alongside post-contrast MPFLAIR images and hyperintensities on post-contrast images only, found in the leptomeningeal space, and were classified as LME (example in Figure 1(b)-(d)). LME foci were classified as "spread/fill" (amorphous in shape, spread into the subarachnoid space and/or filling a sulcus) or "nodular" (restricted to one small, spherical shaped region). Spread/fill foci were further subdivided into those found within sulci ("spread/fillsulcal"), between a gyrus and the dura ("spread/ fill-gyral"), and surrounding brainstem or cerebellar structures ("spread/fill-infratentorial"). Images of LME subtypes are found in Figure 2.

Our methodology for identification of CLs was also identical to that previously described by our group and others. ${ }^{12,14}$ In brief, regions of cortical 


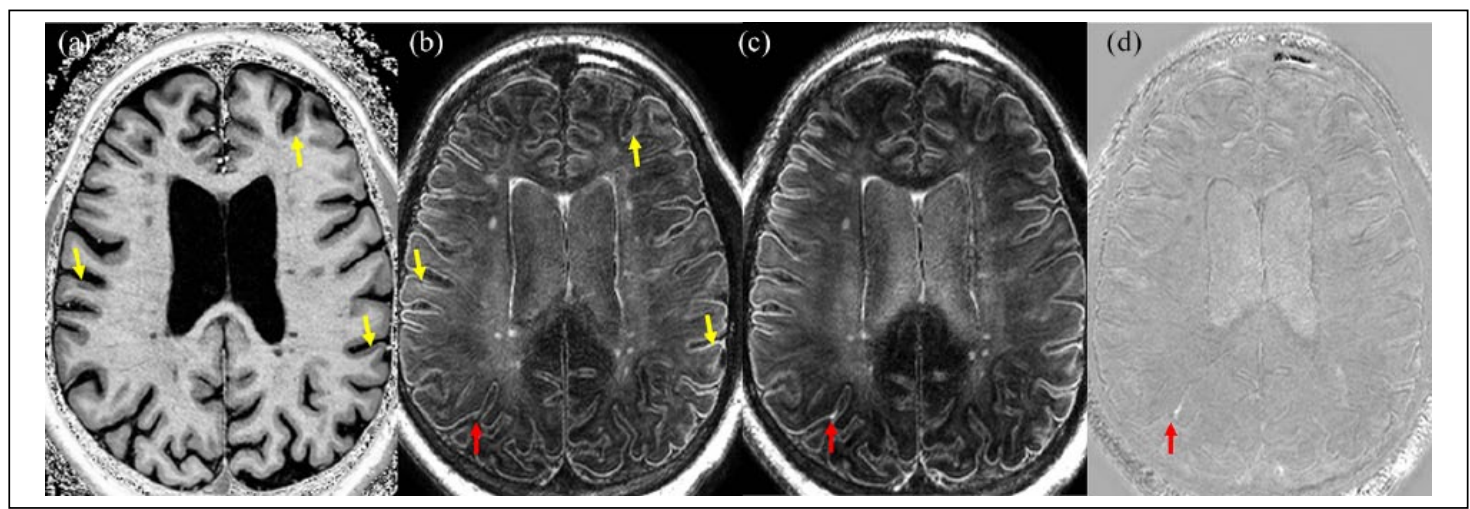

Figure 1. Example of process for identification of cortical lesions and leptomeningeal enhancement. Shown are axial pre-contrast MP2RAGE T1-weighted (a), pre-contrast MPFLAIR (b), post-contrast MPFLAIR (c), and subtraction MPFLAIR (d) images from a 53-year-old man with relapsing-remitting MS. Yellow arrows indicate cortical lesions noted on T1-weighted images (a) and their corresponding location in (b). Red arrows indicate the location of leptomeningeal enhancement found on the subtraction image (d) and its corresponding location on pre-contrast (b) and post-contrast (c) MPFLAIR.

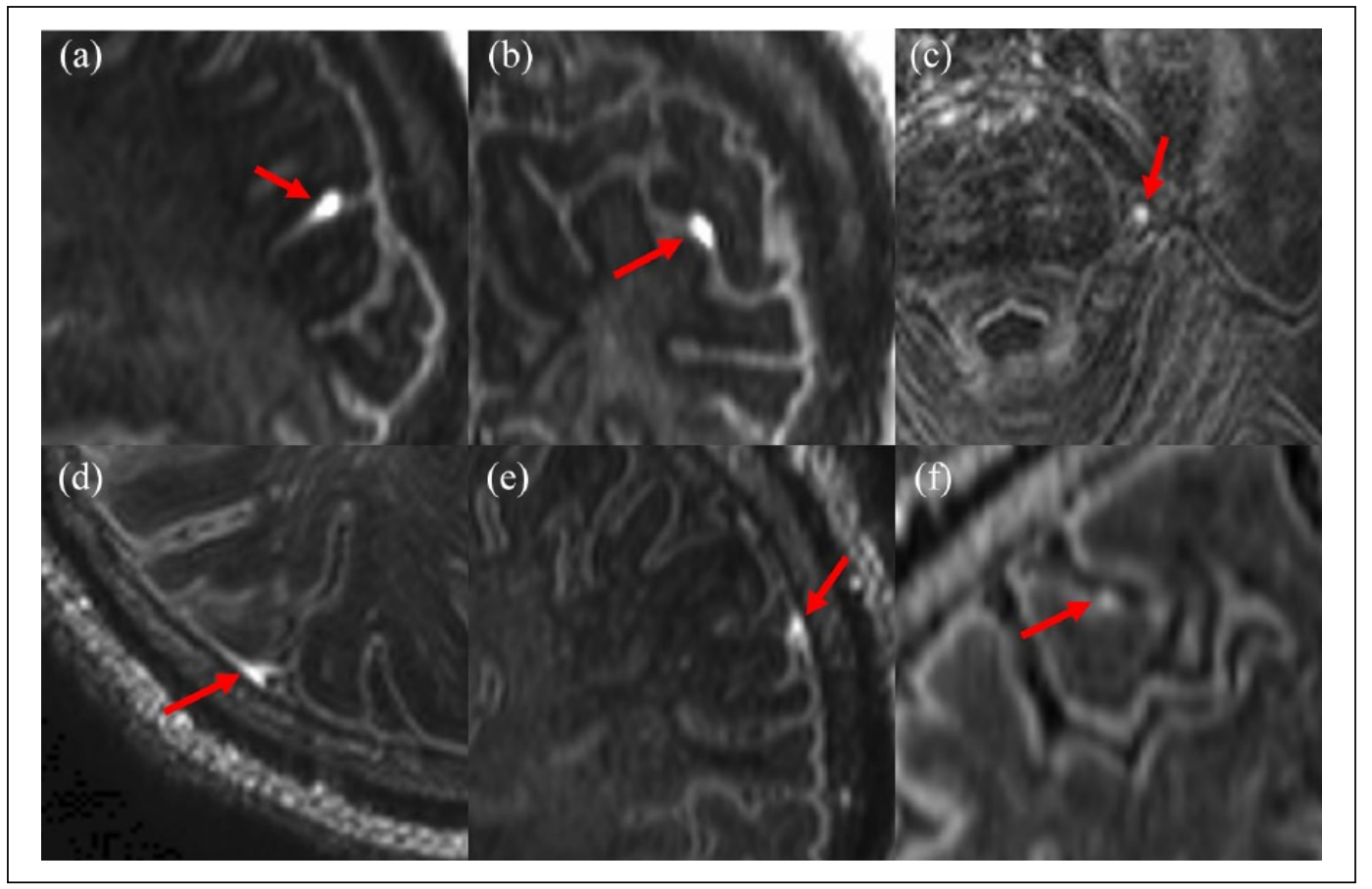

Figure 2. Examples of meningeal enhancement patterns. Shown are images (magnified and cropped) from post-contrast MPFLAIR. Red arrows indicate foci of leptomeningeal enhancement (LME). An example of "spread/fill-sulcal" LME is shown in sagittal (a) and coronal (b) view. (c) A "spread/fill-infratentorial" focus of enhancement adjacent to the pons. An example of "spread/fill-gyral" LME is shown in axial (d) and coronal (e) view. A focus of "nodular" LME is shown in (f).

hypointensity were demarcated on the T1-w MP2RAGE image and MPFLAIR was used for confirmation (hypointensity on T1-w must have had some abnormal signal on MPFLAIR - examples in Figure 1(a)). CLs were subclassified, as previously described, ${ }^{12}$ into those that were leukocortical, intracortical, or subpial (Figure 3). GM lesions in the hippocampus were additionally classified as "hippocampal" (Figure 3 and additional examples in Supplemental Figure e-1). CL masks were handdrawn using semi-automated region-growing paint tools in MIPAV. 


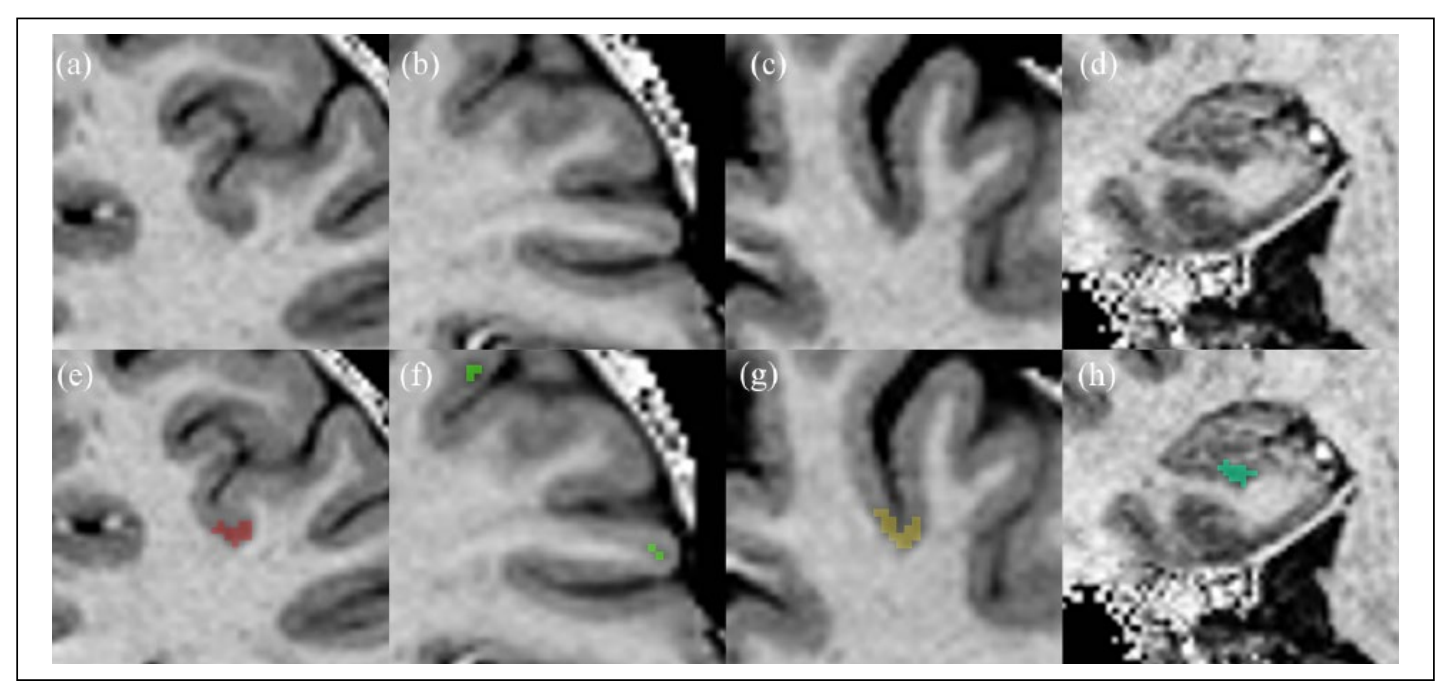

Figure 3. Examples of cortical lesion subtypes and cortical lesion masking: (a, e) leukocortical, (b, f) intracortical, (c, g) subpial, and $(\mathrm{d}, \mathrm{h})$ hippocampal. Cortical lesions were identified as hypointensities on T1w MP2RAGE images with associated hyperintensity on MPFLAIR (not shown). The upper panel is unmarked, and the lower panel shows the lesion area is inpainted as a colored mask.

To increase sensitivity and overcome any issues related to inter-rater variability, labeling, classification, and mask drawing were performed in an iterative process, with simultaneous review, editing, and consensus by multiple authors (D.M.H., S.J., and I.I. for LME and D.M.H., M.I., and E.E.O. for CLs). Each consensus panel included an experienced neuroradiologist (I.I. and E.E.O.).

A brain image processing and segmentation pipeline were built in the JIST environment, including tools from the CBS Tools processing package ${ }^{24}$ and the Lesion Topology-Preserving Anatomical Segmentation (Lesion-TOADS) brain segmentation algorithm. ${ }^{25}$ Segmentation was performed after lesion filling by manually drawn WM lesion masks. Segmentation masks were used for volume calculations. Cortical thickness maps were taken from the Cortical Reconstruction Using Implicit Surface Evolution (CRUISE) cortical extraction module in the CBS Tools package. ${ }^{24}$ Visual review of cortical thickness maps noted occasional errors in designation of the location of sulcal folds in the inferior temporal lobes (likely due to signal dropout and image noise in this region due to head coil location and field inhomogeneity), resulting in over-exaggeration of cortical thickness in this region. To accommodate for this, all voxels with thickness of $>5 \mathrm{~mm}$ were excluded from the thickness map for thickness calculations.

\section{Statistical analysis}

Statistical analysis was performed using Stata 10.0 IC (StataCorp, College Station, TX, USA). Demographic and imaging characteristics were analyzed for normality by the Shapiro-Wilk testing, which revealed that most variables had non-normal distribution. Prospective relationships were analyzed for linearity and constant variance by visual inspection of data plots, which revealed that most relationships were not clearly linear and/or with constant variance. Accordingly, non-parametric tests were used for all analyses. Group differences were assessed by the Wilcoxon rank-sum testing. Comparisons of proportions were assessed by chi-square test and correlation testing was performed using the Spearman rank correlations. Raw volumes for WM lesions, CLs, cortical GM, and cerebral WM are reported. However, normalized volumes (divided by intracranial volume) were used for statistical comparisons. Because of the small sample size and exploratory nature of the study, adjustments for multiple comparisons were not performed. ${ }^{26}$

\section{Results}

Demographic and clinical characteristics are found in Table 1. The cohort included 41 MS participants (31 RRMS, 5 SPMS, and 5 PPMS) and 5 healthy volunteers. Most MS participants were on disease-modifying therapy at the time of their study visit $(78.1 \%)$ and were moderately disabled (median EDSS 3.0).

Neuroimaging analysis results are summarized in Table 1. All MS participants had CLs, with a median of 23 (range 2-82) lesions per scan. There were nonsignificant trends toward higher CL count and volume 
Table 1. Demographic, clinical, and imaging characteristics of study population.

\begin{tabular}{|c|c|c|c|c|}
\hline & $\begin{array}{l}\text { All MS participants } \\
(n=41)\end{array}$ & $\begin{array}{l}\text { RRMS participants } \\
(n=31)\end{array}$ & $\begin{array}{l}\text { Progressive MS } \\
\text { participants }(n=10)\end{array}$ & $\begin{array}{l}\text { Healthy volunteers } \\
(n=5)\end{array}$ \\
\hline \multicolumn{5}{|l|}{ Demographic/clinical characteristics } \\
\hline Age, mean (SD) & $46.0(11.4)$ & $43.8(11.7)$ & $52.8 *(7.6)$ & $44.4(11.4)$ \\
\hline \multicolumn{5}{|l|}{ Sex } \\
\hline Female $(\%)$ & $27(66)$ & $20(65)$ & $7(70)$ & $1 * *(20)$ \\
\hline Male $(\%)$ & $14(34)$ & $11(36)$ & $3(30)$ & $4 * *(80)$ \\
\hline MS subtype & & & & $\mathrm{N} / \mathrm{A}$ \\
\hline RRMS (\%) & $31(76)$ & $31(100)$ & & \\
\hline SPMS (\%) & $5(12)$ & & $5(50)$ & \\
\hline PPMS (\%) & $5(12)$ & & $5(50)$ & \\
\hline On disease-modifying therapy (\%) & $32(78)$ & $25(81)$ & $7(70)$ & N/A \\
\hline Disease duration, mean (SD) & $11.4(8.6)$ & $11.1(8.9)$ & $12.2(8.3)$ & N/A \\
\hline EDSS score, median (range) & $3.0(1-6.5)$ & $2.5(1-6)$ & $5.75 *(3-6.5)$ & $\mathrm{N} / \mathrm{A}$ \\
\hline \multicolumn{5}{|l|}{ CLs } \\
\hline $\begin{array}{l}\text { Leukocortical CL count, median } \\
\text { (range) }\end{array}$ & $17(2-69)$ & $16(2-52)$ & $24.5(6-69)$ & $0 * *(\mathbf{0}-3)$ \\
\hline $\begin{array}{l}\text { Leukocortical CL volume, median } \\
\text { (range) }\end{array}$ & $183.6(18.2-515.6)$ & $179.9(18.2-429.1)$ & $253.6(56.0-515.6)$ & $0 * *(0-35.5)$ \\
\hline $\begin{array}{l}\text { Intracortical CL count, median } \\
\text { (range) }\end{array}$ & $4(0-13)$ & $4(0-13)$ & $6(0-12)$ & $0 * *(0-2)$ \\
\hline $\begin{array}{l}\text { Intracortical CL volume, median } \\
\text { (range) }\end{array}$ & $22.5(0-91.1)$ & $22.5(0-91.1)$ & $23.0(0-58.3)$ & $0 * *(0-10.3)$ \\
\hline Subpial CL count, median (range) & $2(0-7)$ & $2(0-6)$ & $2(0-7)$ & $0 * *(0-1)$ \\
\hline Subpial CL volume, median (range) & $50.0(0-708.7)$ & $50.0(0-215.4)$ & $68.4(0-708.7)$ & $0 * *(0-15.6)$ \\
\hline $\begin{array}{l}\text { Hippocampal CL count, median } \\
\text { (range) }\end{array}$ & $1(0-7)$ & $1(0-7)$ & $0(0-5)$ & $0 * *(0)$ \\
\hline $\begin{array}{l}\text { Hippocampal CL volume, median } \\
\text { (range) }\end{array}$ & $9.3(0-172.0)$ & $17.6(0-155.7)$ & $0(0-172.0)$ & $0 * *(0)$ \\
\hline Total CL count, median (range) & $23(2-82)$ & $23(2-69)$ & $36(6-82)$ & $0 * *(0-6)$ \\
\hline Total CL volume, median (range) & 323.7 (18.2-1356.5) & $296.2(18.2-641.1)$ & $429.4(56.0-1356.5)$ & $0 * *(0-61.3)$ \\
\hline \multicolumn{5}{|l|}{ Other MRI measures } \\
\hline Cortical GM volume, median (range) & $\begin{array}{l}471,934.3 \\
(400,895.9-555,095.6)\end{array}$ & $\begin{array}{l}471,934.3 \\
(410,096.6-555,095.6)\end{array}$ & $\begin{array}{l}475,994.6 \\
(400,895.9-523,555.3)\end{array}$ & $\begin{array}{l}509,291.7 \\
(426,971.8-541,186.9)\end{array}$ \\
\hline $\begin{array}{l}\text { Mean cortical thickness, median } \\
\text { (range) }\end{array}$ & $3.41(3.09-3.65)$ & $3.42(3.12-3.65)$ & $3.38(3.09-3.52)$ & $3.37(3.20-3.60)$ \\
\hline $\begin{array}{l}\text { Cerebral WM volume, median } \\
\text { (range) }\end{array}$ & $\begin{array}{l}445,652.8 \\
(373,890.3-544,424.1)\end{array}$ & $\begin{array}{l}445,505.9 \\
(373,890.3-544,424.1)\end{array}$ & $\begin{array}{l}467,259.6 \\
(378,126.2-528,407.4)\end{array}$ & $\begin{array}{l}477,281.9 \\
(433,642.6-587,932.4)\end{array}$ \\
\hline WM lesion volume, median (range) & $\begin{array}{l}2821.4 \\
(51.7-19,385.8)\end{array}$ & $\begin{array}{l}4590.7 \\
(51.7-19,175.7)\end{array}$ & $\begin{array}{l}2669.3 \\
(620.6-19,385.8)\end{array}$ & $\begin{array}{l}28.82665 * * \\
(0-1188.9)\end{array}$ \\
\hline \multicolumn{5}{|l|}{ Meningeal enhancement patterns } \\
\hline \multicolumn{5}{|l|}{ Nodular } \\
\hline Mean (SD) & $0.4(0.7)$ & $0.6(0.8)$ & $0(0)$ & $0.2(0.45)$ \\
\hline Median (range) & $0(0-2)$ & $0(0-2)$ & $0 *(\mathbf{0})$ & $0(0-1)$ \\
\hline$N$ cases with pattern $(\%)$ & $13(32)$ & $13(42)$ & $0 *(0)$ & $1(20)$ \\
\hline$N$ cases with $>1$ foci $(\%)$ & $5(12)$ & $5(16)$ & $0(0)$ & $0(0)$ \\
\hline \multicolumn{5}{|l|}{ Spread/fill-sulcal } \\
\hline Mean (SD) & $1.4(1.9)$ & $1.4(2.1)$ & $1.4(1.6)$ & $0.4(0.55)$ \\
\hline Median (range) & $1(0-10)$ & $1(0-10)$ & $1(0-4)$ & $0(0-1)$ \\
\hline$N$ cases with pattern $(\%)$ & $24(59)$ & $18(58)$ & $6(60)$ & $2(40)$ \\
\hline$N$ cases with $>1$ foci $(\%)$ & $14(34)$ & $10(32)$ & $4(40)$ & $0(0)$ \\
\hline Spread/fill-gyral & & & & \\
\hline
\end{tabular}


Table 1. (Continued)

\begin{tabular}{|c|c|c|c|c|}
\hline & $\begin{array}{l}\text { All MS participants } \\
(n=41)\end{array}$ & $\begin{array}{l}\text { RRMS participants } \\
(n=31)\end{array}$ & $\begin{array}{l}\text { Progressive MS } \\
\text { participants }(n=10)\end{array}$ & $\begin{array}{l}\text { Healthy volunteers } \\
(n=5)\end{array}$ \\
\hline Mean (SD) & $1.6(1.8)$ & $1.6(1.5)$ & $1.7(2.5)$ & $0 * *(0)$ \\
\hline Median (range) & $1(0-6)$ & $2(0-5)$ & $0.5(0-6)$ & $0 * *(0)$ \\
\hline$N$ cases with pattern $(\%)$ & $25(61)$ & $20(65)$ & $5(50)$ & $0 * *(0)$ \\
\hline$N$ cases with $>1$ foci $(\%)$ & $20(49)$ & $17(55)$ & $3(30)$ & $0 * *(0)$ \\
\hline \multicolumn{5}{|l|}{ Spread/fill-infratentorial } \\
\hline Mean (SD) & $0.1(0.3)$ & $0.1(0.3)$ & $(0.3)$ & $0(0)$ \\
\hline Median (range) & $0(0-1)$ & $0(0-1)$ & $0(0-1)$ & $0(0)$ \\
\hline$N$ cases with pattern $(\%)$ & $4(10)$ & $3(10)$ & $1(10)$ & $0(0)$ \\
\hline$N$ cases with $>1$ foci $(\%)$ & $0(0)$ & $0(0)$ & $0(0)$ & $0(0)$ \\
\hline \multicolumn{5}{|l|}{ Spread/fill—any } \\
\hline Mean (SD) & $3.1(3.0)$ & $3.1(2.9)$ & $3.2(3.3)$ & $0.4 * *(0.55)$ \\
\hline Median (range) & $2(0-12)$ & $2(0-12)$ & $2(0-9)$ & $0 * *(0-1)$ \\
\hline$N$ cases with pattern $(\%)$ & $31(76)$ & $23(74)$ & $8(80)$ & $2(40)$ \\
\hline$N$ cases with $>1$ foci $(\%)$ & $25(61)$ & $20(65)$ & $5(50)$ & $0 * *(0)$ \\
\hline \multicolumn{5}{|l|}{ LME_-any pattern } \\
\hline Mean (SD) & $3.6(3.1)$ & $3.7(3.1)$ & $3.2(3.3)$ & $0.6 * *(0.55)$ \\
\hline Median (range) & $3(0-14)$ & $4(0-14)$ & $2(0-9)$ & $1 * *(0-1)$ \\
\hline$N$ cases with pattern $(\%)$ & $33(81)$ & $25(81)$ & $8(80)$ & $3(60)$ \\
\hline$N$ cases with $>1$ foci $(\%)$ & $27(66)$ & $22(71)$ & $5(50)$ & $0 * *(0)$ \\
\hline \multicolumn{5}{|c|}{$\begin{array}{l}\text { MS: multiple sclerosis; SD: standard deviation; RRMS: relapsing-remitting multiple sclerosis; SPMS: secondary progressive multiple sclerosis; PPMS: } \\
\text { primary progressive multiple sclerosis; EDSS: Expanded Disability Status Scale; CL: cortical lesion; GM: gray matter; WM: white matter; LME: } \\
\text { leptomeningeal enhancement; MRI: magnetic resonance imaging. } \\
\text { All volumes are reported in unit of cubic millimeter. Raw volumes are reported, but normalized (to intracranial volume) values were used for statistical } \\
\text { comparison as to adjust for head size. } \\
{ }^{*} p<0.05 \text { for difference between RRMS and progressive MS. }{ }^{* *} p<0.05 \text { for difference between MS and healthy volunteers. }\end{array}$} \\
\hline
\end{tabular}

in those with progressive forms ofMS(SPMS + PPMS), along with smaller cortical GM and WM lesion volumes in progressive MS. Healthy volunteers had almost no CLs (median 0 (0-6)) (Table 1). Only three (7.4\%) subjects had contrast-enhancing WM lesions.

Most MS participants (80.5\%) displayed at least 1 focus of LME on post-contrast MPFLAIR (Table 1). Spread/fill-gyral and spread/fill-sulcal were the most common LME patterns, appearing in $25(61.0 \%)$ and $24(58.5 \%)$ subjects, respectively. One LME focus was found in three of five healthy volunteers (one case with a nodular focus and two cases with one spread/ fill-sulcal focus each). Median LME foci count was greater in MS cases (3 (0-14)) than in healthy volunteers $(0(0-1), p=0.030)$. No healthy volunteers had $>1$ LME focus, whereas 27 of $41(65.8 \%)$ of MS participants had $>1$ LME focus $(p=0.004)$. Multiple LME foci $(>1)$ was seen mostly for spread/fill (25/41 MS cases, $61.0 \%$ ), with a median of two such foci (range $0-12$ ) per MS subject. Only 5 of $41(12.2 \%)$ of MS subjects had multiple $(>1)$ nodular foci.

Except for spread/fill-sulcal LME and hippocampal lesion count $(\rho=0.32, p=0.042)$, there were no significant correlations between LME foci and CL count/volume, WM lesion volume, and cortical GM volume (Supplemental Table e-1; Supplemental Figure e-2) in the full MS cohort. However, mean cortical thickness showed significant negative correlations with spread/fill-sulcal, spread/fill-gyral, any spread/ fill, and any LME foci count. When the MS cohort was analyzed containing only those participants with RRMS (Table 2; Supplemental Figure e-3), significant correlations between hippocampal CL count and volume with the number of spread/fill-sulcal and overall spread/fill pattern LME foci were seen. However, no correlations were found between any of the neocortical CL subtypes (leukocortical, intracortical, subpial) and the number of LME foci in the RRMS cohort. The number of spread/fill foci (along with sulcal and infratentorial subtypes) and the overall number of LME foci showed significant negative correlations with cortical GM volume in the RRMS cohort. Mean cortical thickness negatively correlated with all forms of LME except nodular in RRMS subjects.

Since up to 1 focus of LME was found in some healthy volunteers, and thus, 1 focus may not necessarily be pathologic, group comparisons were performed for 
Table 2. Correlation matrix for RRMS participants only.

\begin{tabular}{|c|c|c|c|c|c|c|}
\hline & Nodular count & Spread/fill-sulcal & Spread/fill-gyral & $\begin{array}{l}\text { Spread/fill- } \\
\text { infratentorial }\end{array}$ & $\begin{array}{l}\text { Spread/ } \\
\text { fill count }\end{array}$ & $\begin{array}{l}\text { LME- } \\
\text { any count }\end{array}$ \\
\hline Leukocortical CL count & 0.13 & 0.30 & 0.01 & 0.13 & 0.17 & 0.16 \\
\hline Leukocortical CL volume & 0.33 & 0.04 & 0.15 & 0.06 & 0.12 & 0.18 \\
\hline Intracortical CL count & 0.04 & 0.28 & 0.04 & $<-0.01$ & 0.18 & 0.16 \\
\hline Intracortical CL volume & 0.07 & 0.12 & 0.01 & -0.09 & 0.06 & 0.05 \\
\hline Subpial CL count & 0.07 & 0.14 & -0.10 & -0.13 & 0.03 & 0.07 \\
\hline Subpial CL volume & 0.05 & 0.15 & 0.09 & -0.12 & 0.14 & 0.17 \\
\hline Hippocampal CL count & -0.17 & $0.53 * *$ & 0.33 & 0.19 & $0.46 * *$ & $0.39 *$ \\
\hline Hippocampal CL volume & -0.17 & $0.43 *$ & 0.31 & 0.12 & $0.38 *$ & 0.31 \\
\hline Total CL count & 0.09 & 0.32 & 0.03 & 0.07 & 0.20 & 0.19 \\
\hline Total CL volume & 0.17 & 0.20 & 0.23 & -0.01 & 0.24 & 0.27 \\
\hline Cortical GM volume & -0.30 & $-0.41 *$ & -0.32 & $-0.37 *$ & $-0.44 *$ & $-0.49 * *$ \\
\hline Mean cortical thickness & 0.07 & $-0.45 *$ & $-0.57 * *$ & $-0.42 *$ & $-0.64 * *$ & $-0.59 * *$ \\
\hline Cerebral WM volume & 0.07 & 0.13 & 0.20 & $0.38 *$ & 0.20 & 0.21 \\
\hline WM lesion volume & 0.09 & 0.28 & 0.14 & 0.17 & 0.20 & 0.24 \\
\hline \multicolumn{7}{|c|}{$\begin{array}{l}\text { RRMS: relapsing-remitting multiple sclerosis; LME: leptomeningeal enhancement; CL: cortical lesion; GM: gray matter; WM: white matter. } \\
\text { The Spearman correlation } \rho \text { value is shown. All volumes used in statistical analysis were normalized to intracranial volume to adjust for head size. Analysis is } \\
\text { performed in RRMS participants only. }\end{array}$} \\
\hline
\end{tabular}

MS participants with $>1$ focus of LME versus those with $\leqslant 1$ focus. No significant differences in CL burden were found in the full MS cohort comparing these two groups (Supplemental Table e-2). Mean cortical thickness was reduced in participants with $>1$ spread/ fill LME focus $(3.36(3.11-3.56) \mathrm{mm})$ compared to those with $\leqslant 1(3.47(3.09-3.65) \mathrm{mm} ; p=0.035)$. Some significant differences were seen when performing the analysis only in those with RRMS (Table 3). Hippocampal lesion count was greater in those with $>1$ foci of spread/fill-sulcal LME (median 2 $(1-7))$ than those with $<1$ focus (median $1(0-6)$, $p=0.016)$. However, hippocampal lesion volume was lower in those with $>1$ focus of nodular enhancement (median $0 \mathrm{~mm}^{3}(0-13.9)$ ) compared to those with $\leqslant 1$ focus $\left(25.5 \mathrm{~mm}^{3}(0-155.7), p=0.030\right)$. RRMS participants with both $>1$ focus of spread/fill-sulcal LME or $>1$ focus of any LME type had reduced cortical GM volumes compared to those with $\leqslant 1$ focus. WM lesion volume was greater in those with $>1$ focus of spread/fill-sulcal LME $\quad\left(10,229.3 \mathrm{~mm}^{3} \quad(1007.3-\right.$ $19,175.7))$ than those with $\leqslant 1$ focus $\left(2759.7 \mathrm{~mm}^{3}\right.$ (51.7-18,380.5), $p=0.047)$. Mean cortical thickness was significantly reduced in RRMS participants with $>1$ focus of LME of all types except nodular and spread/fill-infratentorial.

\section{Discussion}

A clear link between CLs and LME was not seen in this analysis, which contrasts with hypotheses emerging from pathologic case series in MS. This discrepancy suggests that meningeal inflammation and CL formation may not be as intricately coupled as suggested by histopathology. Our data demonstrate a robust relationship, however, between LME and reduced cortical GM volume and mean thickness, which is supportive of pathologic data suggestive of links between meningeal inflammation and more widespread neurodegenerative processes rather than focal lesions. Alternatively, our results may reveal limitations in imaging technology or a lack of true biological surrogacy between proposed neuroimaging biomarkers for CLs and meningeal inflammation and ground-truth pathology.

Although the advent of ultra-high-field MRI has improved CL detection, pathology-imaging studies show that not all CLs are visible on MRI, even at 9.4 Tesla (9.4T). ${ }^{27}$ This is especially true for subpial demyelination, which is the predominant form of CL, yet is the most difficult to visualize on MRI., ${ }^{2,14}$ Given that the strongest relationships seen at autopsy between meningeal inflammation and cortical pathology are for subpial lesions, ${ }^{6}$ technological limitations may impede the ability to recapitulate such relationships in vivo. Although the MP2RAGE technique used in this study previously showed superiority to other sequences for CL detection, this superiority was mainly seen for leukocortical and juxtacortical lesions. ${ }^{14}$ Magnetic susceptibility-weighted images may be better suited for subpial CLs - with previous data showing detection of both focal and 


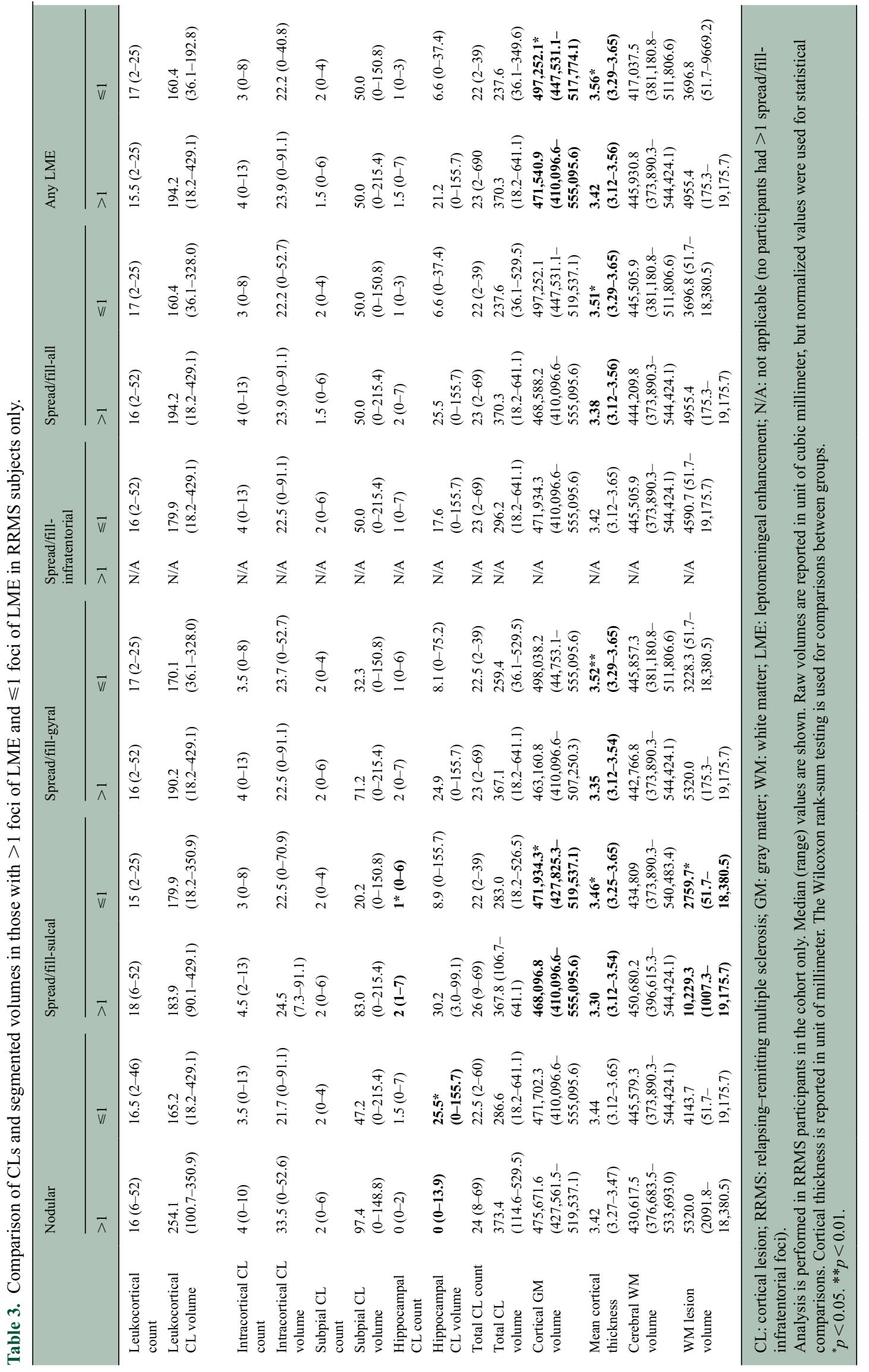


diffuse subpial pathologies by such techniques. ${ }^{28,29} \mathrm{~A}$ head-to-head comparison between MP2RAGE and susceptibility-weighted gradient-recalled echo (GRE) for $\mathrm{CL}$ detection showed that some subpial lesions detected by GRE are not seen on MP2RAGE and vice versa. ${ }^{14}$ Quantitative susceptibility mapping (QSM), a susceptibility-weighted MRI analysis technique, may also provide information on both subpial demyelination and iron accumulation in activated microglia at the subpial surface. ${ }^{29}$ Thus, a combination of both MP2RAGE and QSM may be necessary to more accurately quantify subpial CLs in MS. The lack of multi-modal MRI techniques in this study thus may limit conclusions regarding a lack of relationship between LME and subpial CLs, although this should not limit our conclusions regarding other CL subtypes.

An alternate reason for the lack of strong correlations seen between focal CLs and LME may be a lack of direct surrogacy of LME for meningeal inflammation. Although the presence of gadolinium in the leptomeningeal space on post-contrast, delayed-acquisition FLAIR was shown to co-localize with meningeal inflammation at autopsy, such data are limited to only two patients in one study. ${ }^{15}$ Without replication and larger samples, it is premature to call LME a definitive biomarker of meningeal inflammation in MS. The presence of similar findings on post-contrast FLAIR in other neurologic conditions that are not associated with meningeal inflammation, such as traumatic brain injury, stroke, and after endovascular coiling of cerebral aneurysms, suggests that any process that impairs the meningeal blood-brain barrier may trigger leakage of gadolinium into cerebrospinal fluid (CSF $)^{30-32}$. Furthermore, the presence of up to 1 focus of LME in healthy volunteers in this study and minimal LME seen in prior descriptions of control subjects at $7 \mathrm{~T}^{16}$ suggest that not all LME may be pathologic. ${ }^{33}$ Even if LME is triggered by local meningeal inflammation, it is still unclear what aspect of meningeal inflammation is being visualized. Meningeal inflammation in MS occurs as both diffusely and discrete ectopic lymphoid follicles, 4,5 and meningeal fibrosis may need to accompany inflammation to trap enough gadolinium to be visible in the CSF space. ${ }^{15}$ More imaging-pathology correlation data are needed to determine whether LME occurs in the setting of only one or all of these pathologic changes. Since autopsy studies can correlate the total extent of meningeal inflammation with cortical pathology, neuroimaging studies may fail to replicate such correlations if only the subset of meningeal inflammation is being visualized. Given a lack of autopsy cases, our study cannot answer these questions of pathology-imaging surrogacy. Our findings do suggest, however, that additional histopathologic-imaging studies may be needed to better understand the true meaning of LME on 7T MRI.

Our data support the notion that the link between CL formation and meningeal inflammation in MS may not be entirely ubiquitous or may depend on the stage of MS and phenotypic subtype. Some conflicting case series shows that this relationship is not a foregone conclusion. For example, in an autopsy series of 28 subjects with SPMS and PPMS, Kooi et al. ${ }^{9}$ found no difference in the cellular composition of meninges overlying CLs and normal appearing cortex. Our data may contribute further evidence of a lack of significant relationship between CL formation and meningeal inflammation. Although other pathologic literature confirms a relationship between meningeal inflammation, particularly lymphoid follicles, and CLs in SPMS subjects, ${ }^{5,6}$ conflicting data exist for those with PPMS and early RRMS. ${ }^{9,34,35}$ Most autopsy series in PPMS fail to identify focal meningeal lymphoid follicles - rather demonstrating diffuse meningeal inflammation, ${ }^{4,35}$ which may be more difficult to visualize on MRI. Ectopic lymphoid follicles are found in the meninges of early RRMS, but the presence of follicles correlates with cortical microglial activation and not with CL area. ${ }^{34}$ Thus, at least in RRMS patients, the presence of meningeal follicles may trigger inflammatory processes responsible for neurodegenerative pathology rather than local demyelination. This is supported by our data showing correlations between LME and reduced cortical GM volume and mean thickness, but not with CLs. Indeed, with the addition of our study, a relationship between LME and cortical GM volume, likely indicative of greater GM atrophy, has now been replicated in all descriptions of LME in MS. ${ }^{15-18}$

Although no clear relationship between LME and neocortical CLs was seen in this study, an association between LME and hippocampal lesions was found. While this may be a spurious finding driven by both a small sample size and a small number of lesions per subject, there is clear biologic plausibility. The anatomy of the hippocampus poses a unique situation when performing evaluations of cortical GM. The hippocampus is an archaecortical structure, deriving its embryologic origins from the floor of the temporal horn of the lateral ventricle. The major cortical structures of the hippocampus (regions CA1-4) do not have a pial lining and instead are covered by ependyma in direct contact with ventricular CSF. The dentate gyrus is an exception, which has direct contact with pia mater. Demyelinated lesions were found in 
the hippocampus in $53.3 \%$ of cases in one autopsy series. ${ }^{36}$ Interestingly, some cases showed inflammatory infiltrates in nearby temporal horn choroid plexus and dentate gyrus pia. ${ }^{36}$ Given that choroid plexus is implicated in similar inflammatory processes as meningeal inflammation in $\mathrm{MS},{ }^{37}$ the close proximity to both meninges and choroid plexus may pose a unique situation of dual exposure for the hippocampus, explaining the relationship found in our study between LME and hippocampal lesions. This dual exposure concept is recapitulated in analyses of the mechanism of hippocampal damage in rodent models of MS. ${ }^{38}$ These same animal data also suggest that while dentate gyrus may be susceptible to direct impact from overlying meninges, the remainder of the hippocampus may be more indirectly susceptible to inflammation triggered by dissemination of cytokines in $\mathrm{CSF}^{38}$ - a concept suggested as a mechanism for GM damage in humans and replicated experimentally. 8,39

Although this study's sample size is similar to many 7T MRI studies in MS, larger, multicenter samples may be required to come to generalizable conclusions. This is a clear limitation of this analysis. This limitation is especially relevant to our analysis of progressive MS, which was limited to 10 cases in this cohort. Future work should look to pool resources from multiple centers performing 7T MRI research in MS. Multicenter 7T studies with a standardized imaging protocol would not only help answer the questions such posited here but would help push the use of 7T MRI as a research and clinical tool for MS into the mainstream.

Despite limitations, our findings are a unique contribution to the literature and should spur future research. With much attention now on meningeal inflammation in MS, some have proposed the utilization of LME as an outcome measure for clinical trials, particularly for anti-CD20 monoclonal antibodies. Before moving forward with this concept, our data suggest more work to clarify the true pathologic and clinical implications of LME in MS patients is necessary. Future work may require more robust imaging-histopathologic correlation studies, direct comparisons between techniques at varying magnetic field strength, longitudinal extension studies, and replication of prior data in large, multicenter cohorts.

\section{Acknowledgements}

The authors would like to thank the MRI technicians at the Kirby Center for their work to safely and effectively perform the MRI scans used in this analysis and also thank the study coordinators and study nurses,
Julie Fiol and Kerry Naunton, without whom this work would not be possible.

\section{Declaration of Conflicting Interests}

The author(s) declared the following potential conflicts of interest with respect to the research, authorship, and/or publication of this article: M.I., S.J., A.L.-D., S.C., and J.H. have nothing to disclose. I.I. has received research support from Siemens and Biogen and consulting fees from Alexion. E.E.O. has received research support from NIA 3R01 AG03485208S1. D.M.H. has received research support from EMD Serono and Genentech and consulting fees from UpToDate, Inc., American College of Physicians, EMD Serono, Genentech, Sanofi-Genzyme, and Biogen.

\section{Funding}

The author(s) disclosed receipt of the following financial support for the research, authorship, and/or publication of this article: The study was funded in part by grants from EMD Serono and the National Institutes of Health (NINDS 1K23NS072366-01A1; PI: Harrison). Time for data analysis was also supported by NINDS 1R01NS104403-01 (PI: Harrison) and National Multiple Sclerosis Society pilot grant PP-1804-30760 (PI: Harrison).

\section{ORCID iD}

Daniel M Harrison (iD https://orcid.org/0000-0001 $-8707-2004$

\section{Supplemental Material}

Supplemental material for this article is available online.

\section{References}

1. Peterson JW, Bo L, Mork S, et al. Transected neurites, apoptotic neurons, and reduced inflammation in cortical multiple sclerosis lesions. Ann Neurol 2001; 50(3): 389-400.

2. Geurts JJ and Barkhof F. Grey matter pathology in multiple sclerosis. Lancet Neurol 2008; 7(9): 841-851.

3. Kidd D, Barkhof F, McConnell R, et al. Cortical lesions in multiple sclerosis. Brain 1999; 122(1): 17-26.

4. Howell OW, Reeves CA, Nicholas R, et al. Meningeal inflammation is widespread and linked to cortical pathology in multiple sclerosis. Brain 2011; 134(9): 2755-2771.

5. Magliozzi R, Howell O, Vora A, et al. Meningeal $\mathrm{B}$-cell follicles in secondary progressive multiple 
sclerosis associate with early onset of disease and severe cortical pathology. Brain 2007; 130(4): 1089-1104.

6. Magliozzi R, Howell OW, Reeves C, et al. A gradient of neuronal loss and meningeal inflammation in multiple sclerosis. Ann Neurol 2010; 68(4): 477-493.

7. Lisak RP, Benjamins JA, Nedelkoska L, et al. Secretory products of multiple sclerosis B cells are cytotoxic to oligodendroglia in vitro. J Neuroimmunol 2012; 246(1-2): 85-95.

8. Gardner C, Magliozzi R, Durrenberger PF, et al. Cortical grey matter demyelination can be induced by elevated pro-inflammatory cytokines in the subarachnoid space of MOG-immunized rats. Brain 2013; 136(12): 3596-3608.

9. Kooi EJ, Geurts JJ, van Horssen J, et al. Meningeal inflammation is not associated with cortical demyelination in chronic multiple sclerosis. $J$ Neuropathol Exp Neurol 2009; 68(9): 1021-1028.

10. Torkildsen O, Stansberg C, Angelskar SM, et al. Upregulation of immunoglobulin-related genes in cortical sections from multiple sclerosis patients. Brain Pathol 2010; 20(4): 720-729.

11. Nielsen AS, Kinkel RP, Tinelli E, et al. Focal cortical lesion detection in multiple sclerosis: 3 Tesla DIR versus 7 Tesla FLASH-T2. J Magn Reson Imaging 2012; 35(3): 537-542.

12. Harrison DM, Roy S, Oh J, et al. Association of cortical lesion burden on 7-T magnetic resonance imaging with cognition and disability in multiple sclerosis. JAMA Neurol 2015; 72(9): 1004-1012.

13. Nielsen AS, Kinkel RP, Madigan N, et al. Contribution of cortical lesion subtypes at 7T MRI to physical and cognitive performance in MS. Neurology 2013; 81(7): 641-649.

14. Beck ES, Sati P, Sethi V, et al. Improved visualization of cortical lesions in multiple sclerosis using 7T MP2RAGE. AJNR Am J Neuroradiol 2018; 39(3): 459-466.

15. Absinta M, Vuolo L, Rao A, et al. Gadolinium-based MRI characterization of leptomeningeal inflammation in multiple sclerosis. Neurology 2015; 85(1): 18-28.

16. Harrison DM, Wang KY, Fiol J, et al. Leptomeningeal enhancement at 7T in multiple sclerosis: Frequency, morphology, and relationship to cortical volume. J Neuroimaging 2017; 27(5): 461-468.

17. Zivadinov R, Ramasamy DP, Vaneckova M, et al. Leptomeningeal contrast enhancement is associated with progression of cortical atrophy in MS: A retrospective, pilot, observational longitudinal study. Mult Scler 2017; 23(10): 1336-1345.
18. Makshakov G, Magonov E, Totolyan N, et al. Leptomeningeal contrast enhancement is associated with disability progression and grey matter atrophy in multiple sclerosis. Neurol Res Int 2017; 2017: 8652463.

19. Polman $\mathrm{CH}$, Reingold SC, Banwell B, et al. Diagnostic criteria for multiple sclerosis: 2010 revisions to the McDonald criteria. Ann Neurol 2011; 69(2): 292-302.

20. Kurtzke JF. Rating neurologic impairment in multiple sclerosis: An Expanded Disability Status Scale (EDSS). Neurology 1983; 33(11): 1444-1452.

21. Jonas SN, Izbudak I, Frazier AA, et al. Longitudinal persistence of meningeal enhancement on postcontrast 7T 3D-FLAIR MRI in multiple sclerosis. AJNR Am J Neuroradiol 2018; 39(10): 1799-1805.

22. Marques JP, Kober T, Krueger G, et al. MP2RAGE, a self bias-field corrected sequence for improved segmentation and T1-mapping at high field. Neuroimage 2010; 49(2): 1271-1281.

23. Tustison NJ, Avants BB, Cook PA, et al. N4ITK: Improved N3 bias correction. IEEE Trans Med Imaging 2010; 29(6): 1310-1320.

24. Bazin PL, Weiss M, Dinse J, et al. A computational framework for ultra-high resolution cortical segmentation at 7Tesla. Neuroimage 2014; 93(2): 201-209.

25. Shiee N, Bazin PL, Ozturk A, et al. A topologypreserving approach to the segmentation of brain images with multiple sclerosis lesions. Neuroimage 2010; 49(2): 1524-1535.

26. Rothman KJ. No adjustments are needed for multiple comparisons. Epidemiology 1990; 1(1): 43-46.

27. Schmierer K, Parkes HG, So PW, et al. High field (9.4 Tesla) magnetic resonance imaging of cortical grey matter lesions in multiple sclerosis. Brain 2010; 133(3): 858-867.

28. Cohen-Adad J, Benner T, Greve D, et al. In vivo evidence of disseminated subpial T2* signal changes in multiple sclerosis at $7 \mathrm{~T}$ : A surface-based analysis. Neuroimage 2011; 57(1): 55-62.

29. Castellaro M, Magliozzi R, Palombit A, et al. Heterogeneity of cortical lesion susceptibility mapping in multiple sclerosis. AJNR Am J Neuroradiol 2017; 38(6): 1087-1095.

30. Suthiphosuwan S, Hsu CC and Bharatha A. HARMless: Transient cortical and sulcal hyperintensity on gadolinium-enhanced FLAIR after elective endovascular coiling of intracranial aneurysms. AJNR Am J Neuroradiol 2018; 39(4): $720-726$. 
Visit SAGE journals online journals.sagepub.com/

home/msj

(SAGE journals
31. Latour LL, Kang DW, Ezzeddine MA, et al. Early blood-brain barrier disruption in human focal brain ischemia. Ann Neurol 2004; 56(4): 468-477.

32. Chiara Ricciardi M, Bokkers RP, Butman JA, et al. Trauma-specific brain abnormalities in suspected mild traumatic brain injury patients identified in the first 48 hours after injury: A blinded magnetic resonance imaging comparative study including suspected acute minor stroke patients. J Neurotrauma 2017; 34(1): 23-30.

33. Absinta M, Ha SK, Nair G, et al. Human and nonhuman primate meninges harbor lymphatic vessels that can be visualized noninvasively by MRI. Elife 2017; 6: e29738.

34. Bevan RJ, Evans R, Griffiths L, et al. Meningeal inflammation and cortical demyelination in acute multiple sclerosis. Ann Neurol 2018; 84(6): 829-842.
35. Choi SR, Howell OW, Carassiti D, et al. Meningeal inflammation plays a role in the pathology of primary progressive multiple sclerosis. Brain 2012; 135(10): 2925-2937.

36. Papadopoulos D, Dukes S, Patel R, et al. Substantial archaeocortical atrophy and neuronal loss in multiple sclerosis. Brain Pathol 2009; 19(2): 238-253.

37. Dragunow M. Meningeal and choroid plexus cells: Novel drug targets for CNS disorders. Brain Res 2013; 1501: 32-55.

38. Kyran EL, Robinson C, Kocovski P, et al. Multiple pathological mechanisms contribute to hippocampal damage in the experimental autoimmune encephalomyelitis model of multiple sclerosis. Neuroreport 2018; 29(1): 19-24.

39. Magliozzi R, Howell OW, Nicholas R, et al. Inflammatory intrathecal profiles and cortical damage in multiple sclerosis. Ann Neurol 2018; 83(4): 739-755. 
Figure e-1: Examples of hippocampal lesions.
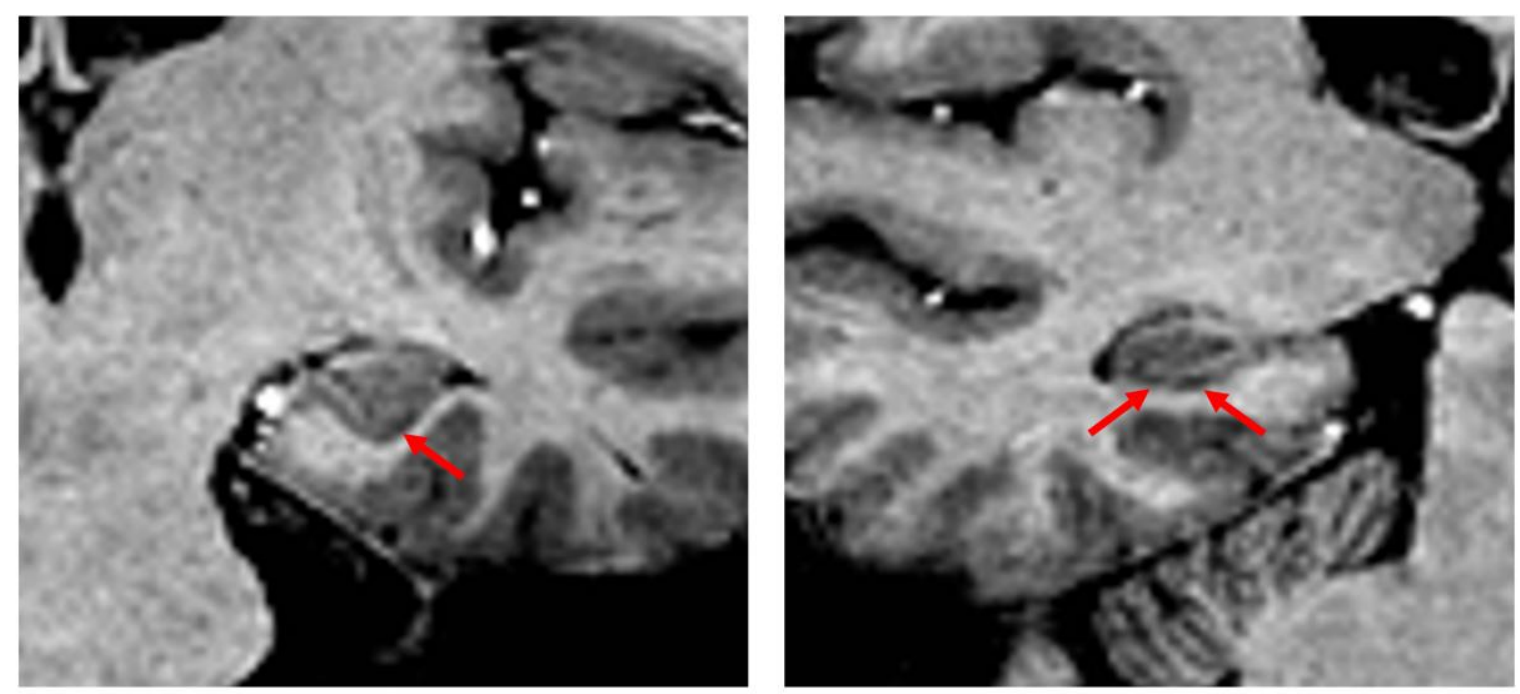

Shown are two examples of MP2RAGE T1-w images (zoomed, cropped) with red arrows indicating hippocampal lesions. 
Figure e-2: Scatter plots for correlation analyses in the full cohort.
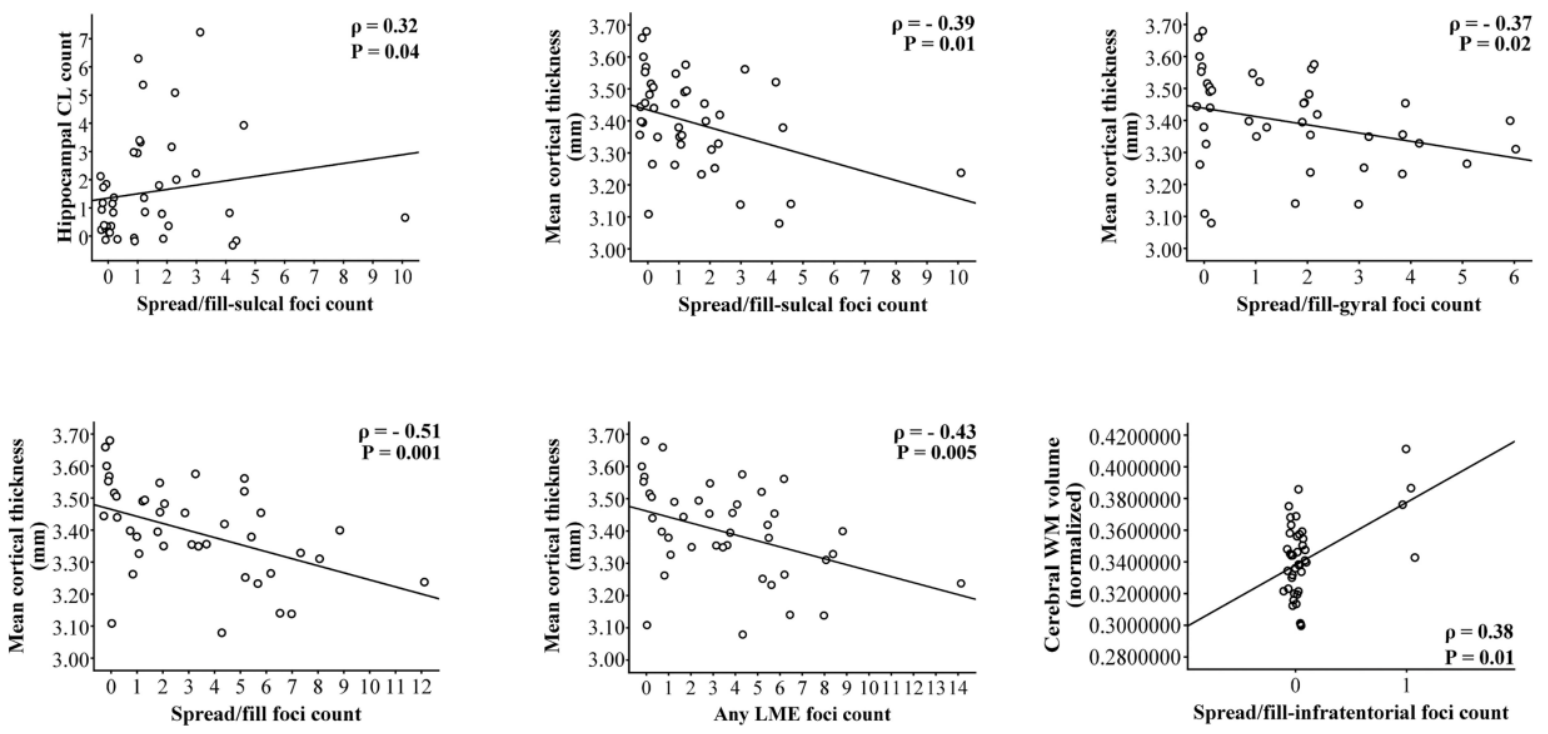

Scatter plots with lines of best fit shown for all significant correlations found in correlation analysis. Spearman rho $(\rho)$ values and levels of significance shown in each plot. 
Figure e-3: Scatter plots for correlation analyses in the RRMS subjects only.
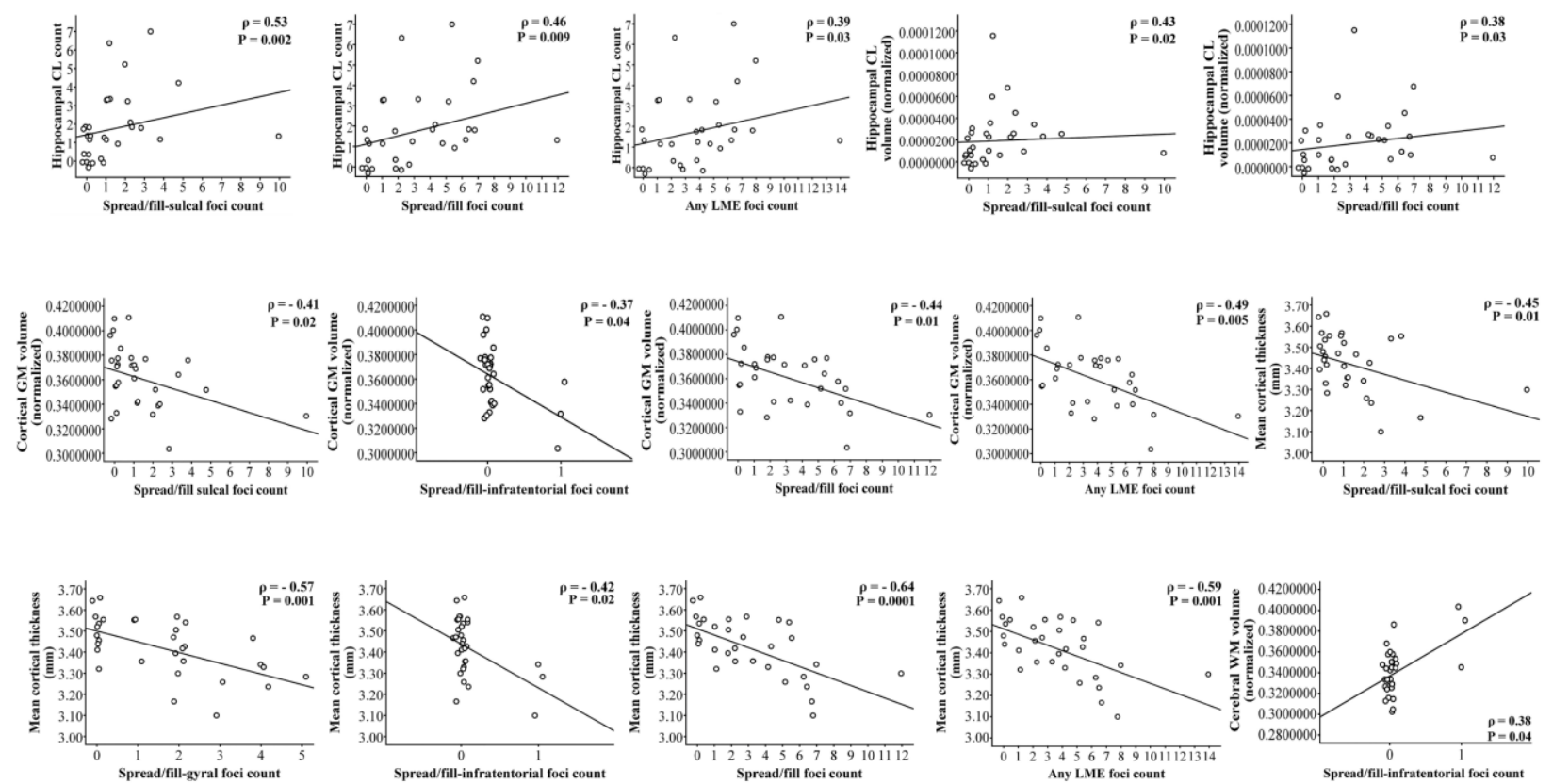

Scatter plots with lines of best fit shown for all significant correlations found in correlation analysis. Spearman rho $(\rho)$ values and levels of significance shown in each plot. 
Table e-1: Correlation matrix in full cohort.

\begin{tabular}{|c|c|c|c|c|c|c|}
\hline & $\begin{array}{l}\text { Nodular } \\
\text { count }\end{array}$ & $\begin{array}{l}\text { Spread/fill- } \\
\text { sulcal }\end{array}$ & $\begin{array}{l}\text { Spread/fill- } \\
\text { gyral }\end{array}$ & $\begin{array}{c}\text { Spread/fill- } \\
\text { infratentorial }\end{array}$ & $\begin{array}{l}\text { Spread/fill } \\
\text { count }\end{array}$ & $\begin{array}{l}\text { LME - Any } \\
\text { count }\end{array}$ \\
\hline $\begin{array}{c}\text { Leukocortical CL } \\
\text { Count }\end{array}$ & 0.02 & 0.28 & -0.07 & -0.04 & 0.11 & 0.09 \\
\hline $\begin{array}{l}\text { Leukocortical CL } \\
\text { Volume }\end{array}$ & 0.14 & 0.16 & -0.02 & -0.11 & 0.08 & 0.11 \\
\hline $\begin{array}{c}\text { Intracortical CL } \\
\text { Count }\end{array}$ & -0.05 & 0.22 & -0.08 & -0.15 & 0.08 & 0.04 \\
\hline $\begin{array}{c}\text { Intracortical CL } \\
\text { Volume }\end{array}$ & 0.02 & 0.12 & -0.11 & -0.21 & $<0.01$ & -0.01 \\
\hline Subpial CL Count & $<-0.01$ & -0.03 & -0.12 & -0.20 & -0.09 & -0.10 \\
\hline $\begin{array}{c}\text { Subpial CL } \\
\text { Volume }\end{array}$ & -0.02 & -0.01 & -0.01 & -0.20 & -0.03 & -0.03 \\
\hline $\begin{array}{c}\text { Hippocampal CL } \\
\text { Count }\end{array}$ & -0.02 & $0.32 *$ & 0.11 & 0.08 & 0.21 & 0.17 \\
\hline $\begin{array}{c}\text { Hippocampal CL } \\
\text { Volume }\end{array}$ & -0.02 & 0.27 & 0.10 & 0.05 & 0.17 & 0.14 \\
\hline Total CL Count & $<0.01$ & 0.27 & -0.06 & -0.08 & 0.11 & 0.09 \\
\hline Total CL Volume & 0.05 & 0.17 & 0.03 & -0.16 & 0.11 & 0.11 \\
\hline $\begin{array}{c}\text { Cortical GM } \\
\text { Volume }\end{array}$ & -0.18 & -0.27 & -0.06 & -0.23 & -0.20 & -0.23 \\
\hline $\begin{array}{c}\text { Mean Cortical } \\
\text { Thickness }\end{array}$ & 0.19 & $-0.39 *$ & $-0.37^{*}$ & -0.29 & $-0.51 * *$ & $-0.43^{* *}$ \\
\hline $\begin{array}{c}\text { Cerebral WM } \\
\text { Volume }\end{array}$ & 0.03 & 0.11 & 0.24 & $0.38 *$ & 0.24 & 0.24 \\
\hline $\begin{array}{l}\text { WM Lesion } \\
\text { Volume }\end{array}$ & 0.14 & 0.22 & 0.07 & 0.06 & 0.13 & 0.16 \\
\hline
\end{tabular}

Spearman correlation $\rho$ value shown. All volumes were normalized to intracranial volume to adjust for head size prior to performing correlation testing. $\mathrm{CL}=$ cortical lesion. $\mathrm{GM}=$ gray matter. $\mathrm{WM}=$ white matter. $\mathrm{LME}=$ leptomeningeal enhancement. ${ }^{*}=\mathrm{p}<0.05 .{ }^{* *}=\mathrm{p}<0.01$. 
Table e-2: Comparison of CLs and segmented volumes in those with $>1$ foci versus $\leq 1$ foci of LME in full cohort.

\begin{tabular}{|c|c|c|c|c|c|c|c|c|c|c|c|c|}
\hline & \multicolumn{2}{|c|}{ Nodular } & \multicolumn{2}{|c|}{ Spread/fill-sulcal } & \multicolumn{2}{|c|}{ Spread/fill-gyral } & \multicolumn{2}{|c|}{$\begin{array}{c}\text { Spread/fill- } \\
\text { infratentorial }\end{array}$} & \multicolumn{2}{|c|}{ Spread/fill-All } & \multicolumn{2}{|c|}{ Any LME } \\
\hline & $>1$ & $\leq 1$ & $>1$ & $\leq 1$ & $>1$ & $\leq 1$ & $>1$ & $\leq 1$ & $>1$ & $\leq 1$ & $>1$ & $\leq 1$ \\
\hline $\begin{array}{c}\text { Leukocortical } \\
\text { Count }\end{array}$ & $\begin{array}{c}16(6- \\
69)\end{array}$ & $17(2-69)$ & $19(6-69)$ & $16(2-39)$ & $\begin{array}{l}15.5(2- \\
69)\end{array}$ & $19(2-39)$ & $\mathrm{N} / \mathrm{A}$ & $17(2-69)$ & $\begin{array}{c}16(2- \\
69)\end{array}$ & $\begin{array}{c}17.5(2- \\
39)\end{array}$ & $16(2-69)$ & $\begin{array}{l}19.5(2- \\
39)\end{array}$ \\
\hline $\begin{array}{l}\text { Leukocortical } \\
\text { CL Volume }\end{array}$ & $\begin{array}{c}254.1 \\
(100.7- \\
350.9) \\
\end{array}$ & $\begin{array}{c}181.2 \\
(18.2- \\
515.6) \\
\end{array}$ & $\begin{array}{c}213.2 \\
(56.0- \\
503.6)\end{array}$ & $\begin{array}{c}182.6 \\
(18.2- \\
515.6) \\
\end{array}$ & $\begin{array}{c}179.9 \\
(18.2- \\
429.1) \\
\end{array}$ & $\begin{array}{c}183.6( \\
36.1- \\
515.6) \\
\end{array}$ & N/A & $\begin{array}{c}183.6 \\
(18.2- \\
515.6) \\
\end{array}$ & $\begin{array}{c}198.1 \\
(18.2- \\
503.6) \\
\end{array}$ & $\begin{array}{c}181.2 \\
(36.1- \\
515.6) \\
\end{array}$ & $\begin{array}{c}198.1 \\
(18.2- \\
503.6) \\
\end{array}$ & $\begin{array}{c}181.2 \\
(36.1- \\
515.6) \\
\end{array}$ \\
\hline $\begin{array}{c}\text { Intracortical } \\
\text { CL Count }\end{array}$ & $4(0-10)$ & $4(0-130$ & $\begin{array}{c}5.5(0- \\
13)\end{array}$ & $4(0-12)$ & $\begin{array}{c}3.5(0- \\
13)\end{array}$ & $5(0-12)$ & N/A & $4(0-13)$ & $4(0-13)$ & $\begin{array}{c}4.5(0- \\
12)\end{array}$ & $4(0-13)$ & $5(0-12)$ \\
\hline $\begin{array}{l}\text { Intracortical } \\
\text { CL Volume }\end{array}$ & $\begin{array}{c}33.5(0- \\
52.7)\end{array}$ & $\begin{array}{c}21.7(0- \\
91.1)\end{array}$ & $\begin{array}{c}24.5(0- \\
91.1)\end{array}$ & $\begin{array}{c}22.5(0- \\
70.9)\end{array}$ & $\begin{array}{c}20.4 \\
(0- \\
91.1)\end{array}$ & $\begin{array}{c}27.2 \\
(0- \\
58.3) \\
\end{array}$ & N/A & $\begin{array}{c}22.5(0- \\
91.1)\end{array}$ & $\begin{array}{c}22.5 \\
(0- \\
91.1)\end{array}$ & $\begin{array}{c}24.7 \\
(0- \\
57.0)\end{array}$ & $\begin{array}{c}22.5 \\
(0- \\
91.1) \\
\end{array}$ & $\begin{array}{c}24.7 \\
(0- \\
57.0)\end{array}$ \\
\hline $\begin{array}{c}\text { Subpial CL } \\
\text { Count }\end{array}$ & $2(0-6)$ & $2(0-7)$ & $1.5(0-6)$ & $2(0-7)$ & $1.5(0-6)$ & $2(0-7)$ & N/A & $2(0-7)$ & $1(0-6)$ & $3(0-7)$ & $1(0-6)$ & $3(0-7)$ \\
\hline $\begin{array}{l}\text { Subpial CL } \\
\text { Volume }\end{array}$ & $\begin{array}{c}97.4(0- \\
148.8)\end{array}$ & $\begin{array}{c}47.7(0- \\
708.70\end{array}$ & $\begin{array}{c}63.5(0- \\
215.4)\end{array}$ & $\begin{array}{c}45.4(0- \\
708.7)\end{array}$ & $\begin{array}{c}63.5 \\
(0- \\
215.4) \\
\end{array}$ & $\begin{array}{c}45.4 \\
(0- \\
708.7) \\
\end{array}$ & N/A & $\begin{array}{c}50.0(0- \\
708.7)\end{array}$ & $\begin{array}{c}18.9 \\
(0-215.4)\end{array}$ & $\begin{array}{c}71.6(0- \\
708.7)\end{array}$ & $\begin{array}{c}18.9 \\
(0- \\
215.4) \\
\end{array}$ & $\begin{array}{c}71.6 \\
(0- \\
708.7) \\
\end{array}$ \\
\hline $\begin{array}{c}\text { Hippocampal } \\
\text { CL Count }\end{array}$ & $0(0-2)$ & $1(0-7)$ & $1.5(0-7)$ & $1(0-6)$ & $1.5(0-7)$ & $1(0-6)$ & N/A & $1(0-7)$ & $1(0-7)$ & $1(0-5)$ & $1(0-7)$ & $1(0-5)$ \\
\hline $\begin{array}{l}\text { Hippocampal } \\
\text { CL Volume }\end{array}$ & $0(0-13.9)$ & $\begin{array}{c}0 \\
0-1)\end{array}$ & $\begin{array}{c}21.2(0- \\
99.1)\end{array}$ & $\begin{array}{l}7.3(0- \\
172.0)\end{array}$ & $\begin{array}{c}15.7 \\
(0- \\
155.7)\end{array}$ & $\begin{array}{c}6.6 \\
(0- \\
172.0)\end{array}$ & N/A & $\begin{array}{l}9.3(0- \\
172.0)\end{array}$ & $\begin{array}{c}13.9 \\
(0- \\
155.7)\end{array}$ & $\begin{array}{l}7.0(0- \\
172.0)\end{array}$ & $\begin{array}{c}9.6 \\
(0- \\
155.7)\end{array}$ & $\begin{array}{c}7.0 \\
(0- \\
172.0)\end{array}$ \\
\hline $\begin{array}{c}\text { Total CL } \\
\text { Count }\end{array}$ & $24(8-69)$ & $23(2-82)$ & $27(6-82)$ & $23(2-54)$ & $\begin{array}{c}22.5(2- \\
82)\end{array}$ & $25(2-54)$ & N/A & $23(2-82)$ & $23(2-82)$ & $\begin{array}{c}23.5(2- \\
54)\end{array}$ & $23(2-82)$ & $25(2-54)$ \\
\hline $\begin{array}{l}\text { Total CL } \\
\text { Volume }\end{array}$ & $\begin{array}{c}373.4 \\
(114.6- \\
529.5) \\
\end{array}$ & $\begin{array}{c}299.9 \\
(18.2- \\
1356.5) \\
\end{array}$ & $\begin{array}{c}367.8 \\
(56.0- \\
641.1) \\
\end{array}$ & $\begin{array}{c}290.3 \\
(18.2- \\
1356.5) \\
\end{array}$ & $\begin{array}{c}350.4 \\
(18.2- \\
641.1) \\
\end{array}$ & $\begin{array}{c}296.2 \\
(36.1- \\
1356.5)\end{array}$ & N/A & $\begin{array}{c}323.7 \\
(18.2- \\
1356.5) \\
\end{array}$ & $\begin{array}{c}367.1 \\
(18.2- \\
641.1) \\
\end{array}$ & $\begin{array}{c}285.8 \\
(36.1- \\
1356.5) \\
\end{array}$ & $\begin{array}{c}367.1 \\
(18.2- \\
641.1) \\
\end{array}$ & $\begin{array}{c}285.8 \\
(36.1- \\
1356.5) \\
\end{array}$ \\
\hline $\begin{array}{c}\text { Cortical GM } \\
\text { Volume }\end{array}$ & $\begin{array}{c}475671.6 \\
(427561.5 \\
- \\
519537.1) \\
\end{array}$ & $\begin{array}{c}471702.3 \\
(400895.9 \\
- \\
555095.6) \\
\end{array}$ & $\begin{array}{c}468096.8 \\
(400895.9 \\
- \\
555095.6) \\
\end{array}$ & $\begin{array}{c}471934.3 \\
(425828.3 \\
- \\
425828.3) \\
\end{array}$ & $\begin{array}{c}464201.4 \\
(400895.9 \\
- \\
507250.3) \\
\end{array}$ & $\begin{array}{c}486036.3 \\
(425828.3 \\
- \\
555095.6) \\
\end{array}$ & N/A & $\begin{array}{c}471934.3 \\
(400895.9 \\
- \\
555095.6) \\
\end{array}$ & $\begin{array}{c}471934.3 \\
(400895.9 \\
- \\
555095.6) \\
\end{array}$ & $\begin{array}{c}478753.2 \\
(425828.3 \\
- \\
523555.3) \\
\end{array}$ & $\begin{array}{c}471934.3 \\
(400895.9 \\
- \\
555095.6) \\
\end{array}$ & $\begin{array}{l}478753.2 \\
(425828.3 \\
- \\
523555.3) \\
\end{array}$ \\
\hline $\begin{array}{c}\text { Mean Cortical } \\
\text { Thickness } \\
\end{array}$ & $\begin{array}{c}3.42 \\
(3.27- \\
\end{array}$ & $\begin{array}{c}3.41(3.09 \\
- \\
\end{array}$ & $\begin{array}{c}3.30 \\
(3.11- \\
\end{array}$ & $\begin{array}{c}3.43 * \\
(3.09- \\
\end{array}$ & $\begin{array}{c}3.35 \\
(3.12- \\
\end{array}$ & $\begin{array}{c}3.46 * \\
(3.09- \\
\end{array}$ & N/A & $\begin{array}{c}3.41(3.09 \\
- \\
\end{array}$ & $\begin{array}{c}3.36 \\
(3.11- \\
\end{array}$ & $\begin{array}{c}3.47^{*} \\
(3.09- \\
\end{array}$ & $\begin{array}{c}3.39 \\
(3.11- \\
\end{array}$ & $\begin{array}{c}3.47 \\
(3.09- \\
\end{array}$ \\
\hline
\end{tabular}




\begin{tabular}{|c|c|c|c|c|c|c|c|c|c|c|c|c|}
\hline & 3.47) & 3.65) & 3.54) & 3.65) & 3.54) & 3.65) & & 3.65) & 3.56) & 3.65) & 3.56) & 3.65) \\
\hline $\begin{array}{c}\text { Cerebral WM } \\
\text { Volume }\end{array}$ & $\begin{array}{c}430617.5 \\
(376683.5 \\
- \\
533693)\end{array}$ & $\begin{array}{c}445930.8 \\
(373890.3 \\
- \\
544424.1)\end{array}$ & $\begin{array}{c}450680.2 \\
(378126.2 \\
- \\
544424.1)\end{array}$ & $\begin{array}{c}445505.9 \\
(373890.3 \\
- \\
540483.4)\end{array}$ & $\begin{array}{c}444209.8 \\
(373890.3 \\
- \\
544424.1)\end{array}$ & $\begin{array}{c}446208.8 \\
(381180.8 \\
- \\
528407.4)\end{array}$ & N/A & $\begin{array}{c}445652.8 \\
(373890.3 \\
- \\
544424.1)\end{array}$ & $\begin{array}{c}445652.8 \\
(373890.3 \\
- \\
544424.1)\end{array}$ & $\begin{array}{c}450383.1 \\
(381180.8 \\
- \\
528407.4)\end{array}$ & $\begin{array}{c}446208.8 \\
(373890.3 \\
- \\
544424.1)\end{array}$ & $\begin{array}{c}444363.8 \\
(381180.8 \\
- \\
528407.4)\end{array}$ \\
\hline $\begin{array}{l}\text { WM Lesion } \\
\text { Volume }\end{array}$ & $\begin{array}{r}5320.0 \\
(2091.8- \\
18380.5)\end{array}$ & $\begin{array}{c}2771.7 \\
(51.7- \\
19385.8)\end{array}$ & $\begin{array}{c}4955.4 \\
(1007.3- \\
19175.7)\end{array}$ & $\begin{array}{c}2747.5 \\
(51.7- \\
19385.8) \\
\end{array}$ & $\begin{array}{c}4569.0 \\
(175.3- \\
19175.7)\end{array}$ & $\begin{array}{c}2747.5 \\
(51.7- \\
19385.8) \\
\end{array}$ & N/A & $\begin{array}{c}2821.4 \\
(51.7- \\
19385.8)\end{array}$ & $\begin{array}{c}3332.3 \\
(175.3- \\
19175.7)\end{array}$ & $\begin{array}{c}2753.6 \\
(51.7- \\
19385.8) \\
\end{array}$ & $\begin{array}{c}3332.3 \\
(175.3- \\
19175.7)\end{array}$ & $\begin{array}{c}2717.2 \\
(51.7- \\
19385.8)\end{array}$ \\
\hline
\end{tabular}

Median (range) values shown. Raw volumes $\left(\mathrm{mm}^{3}\right)$ shown, but normalized values used for statistical comparisons. Mean cortical thickness in $\mathrm{mm}$. Wilcoxon rank sum testing for comparisons between groups. $\mathrm{CL}=$ cortical lesion. $\mathrm{GM}=$ gray matter. $\mathrm{WM}=$ white matter. $\mathrm{LME}=$ leptomeningeal enhancement. $\mathrm{N} / \mathrm{A}=$ not applicable (no participants had $>1$ spread/fill-infratentorial foci). ${ }^{*}=p<0.05 .{ }^{* *}=p<0.01$. 